\title{
Germinação de sementes de um ecótipo de paspalum da região de Guarapuava - Pr
}

\section{Germination of seeds of a paspalum ecotype from Guarapuava, Paraná State}

\author{
Ruy Inacio Neiva de Carvalho ${ }^{1 *}$; Denise Bruginski de Carvalho
}

\section{Resumo}

O objetivo da pesquisa foi verificar o efeito da classificação das cariopses, da escarificação ácida e do tratamento com nitrato de potássio na germinação das sementes de um ecótipo de Paspalum notatum Flügge da região de Guarapuava, Paraná. Adotou-se o delineamento experimental completamente casualizado em arranjo fatorial com três fatores: classe das cariopses (três classes obtidas em soprador de sementes nas aberturas quatro, cinco e seis), tempo de tratamento com ácido sulfúrico concentrado $(0,7,5$ e 15 minutos) e concentração de nitrato de potássio ( 0 e $0,2 \%)$. Foram avaliados a germinação após 7, 14, 21 e 28 dias, o índice de velocidade de germinação e o tempo médio para germinação. A maior germinação obtida foi de $12,2 \%$ para as sementes da classe seis do soprador e escarificadas por 15 minutos. Não ocorreu germinação das sementes da classe quatro que não receberam escarificação ácida e não houve interferência do nitrato de potássio. Concluiu-se que a classificação e a escarificação ácida das cariopses favoreceram a germinação das sementes de P. notatum.

Palavras-Chave: Paspalum notatum. Classificação. Escarificação ácida. Nitrato de potássio.

\begin{abstract}
The objective of this research was to evaluate the effect of the caryopsis classification, the acid scarification and the treatment with potassium nitrate in the seed germination of a Paspalum notatum Flügge ecotype from the Guarapuava region, Paraná State. The experimental design was the completely randomized in a factorial arrangement with three factors: caryopsis classes (three classes gotten in a seed blower in openings four, five and six), sulfuric acid concentrated treatment period $(0,7.5$ and 15 minutes) and potassium nitrate concentration ( 0 and $0.2 \%)$. The seed germination was evaluated after $7,14,21$ and 28 days. The germination percentage, the germination speed index and the average time to germination were evaluated. The best germination obtained was $12.2 \%$ for the seeds of class six scarified for 15 minutes. Seeds from class four and not treated with sulfuric acid did not germinate. There was no interference of potassium nitrate treatment on seed germination. The classification and the acid scarification of the caryopsis were favorable to increase $P$. notatum seed germination.
\end{abstract}

Key words: Paspalum notatum. Classification. Acid scarification. Potassium nitrate.

1 Eng. Agrônomo, Dr., Bolsista de Produtividade em Pesquisa do CNPq, Professor Titular do Centro de Ciências Agrárias e Ambientais da Pontifícia Universidade Católica do Paraná, Campus São José dos Pinhais - Paraná. E-mail: ruy.carvalho@pucpr. br

2 Docente do Curso de Especialização em Gestão dos Recursos Naturais do Centro de Ciências Agrárias e Ambientais da Pontifícia Universidade Católica do Paraná, São José dos Pinhais, Paraná. E-mail: denise.bcarvalho@terra.com.br

* Autor para correspondência 
Entre os principais gêneros de pastagens naturais do Sul do Brasil, encontra-se o Paspalum. Há diversas espécies de crescimento espontâneo ou cultivadas com destaque para $P$. notatum, $P$. plicatulum (QUADROS et al., 2003) e $P$. dilatatum (SCHEFFER-BASSO; TRENTINI; BARÉA, 2007). A ampla adaptação deste gênero possibilitou sua ocorrência em várias outras regiões do Brasil como no cerrado, onde vegetam as espécies $P$. gardnerianum, $P$. pectinatum, $P$. pilosum, $P$. polyphilum, $P$. reduncum, $P$. splendens, $P$. stellatum e $P$. trichostomumI (CARMONA; MARTINS; FÁVERO, 1999), na região Sudeste, com destaque às espécies $P$. arenarium $\mathrm{e}$. vaginatum (MENEZES; ARAUJO, 2004) e na região Norte com a espécie $P$. maritimum (SOUZA FILHO, 2006).

Em pastagens roçadas e melhoradas com pastejo rotativo no Sul do Brasil o P. notatum se sobressai em relação às demais (HERINGER; JACQUES, 2002). O desempenho animal é adequado com esta pastagem (SOARES FILHO; RODRIGUES, 1999), mas a intensidade de pastejo associada à adubação modificam a estrutura da planta (BOGGIANO et al., 1999), suas propriedades espectrais (FONSECA; ROSA; FONTANA, 2002) e sua digestibilidade (HADDAD et al., 1999).

A espécie também é cultivada em várias regiões do Brasil para formação de gramados por ser resistente ao pisoteio, à seca e aos solos pobres (LORENZI; SOUZA, 1999), apesar de ser sensível à geada (MARÇALLO; PELISSARI; MORAES, 2006). Apresenta tolerância ao sombreamento, mas baixa capacidade produtiva nestas condições (ANDRADE et al., 2004). É também utilizada nas entrelinhas de pomares cítricos assegurando às frutíferas relações hídricas adequadas (FIDALSKI et al., 2006) ou como bioindicadora da presença de flúor no solo (OLIVA; FIGUEIREDO, 2005).

A intensa ocorrência de $P$. notatum no Sul do Brasil e sua característica de adaptação às condições ambientais e de cultivo diversas geraram diferentes ecótipos da espécie. No Rio Grande do Sul têm destaque os ecótipos André da Rocha, Capivari e Comum (NABINGER; VIEIRO; COSTA, 1999). No Paraná há plantas do ecótipo de Guarapuava que apresentam crescimento adequado e são mais consumidas pelos animais quando comparadas a outras forrageiras de verão introduzidas.

Plantas do gênero Paspalum apresentam baixo percentual de espiguetas férteis (5 a 24\%) gerando grande ocorrência de espiguetas vazias misturadas à massa de espiguetas colhidas. A diferença de massa entre espiguetas cheias e vazias é superior a $100 \%$ fazendo-se necessário o beneficiamento das sementes por meio da ventilação (CARMONA; MARTINS; FÁVERO, 1999). Porém, mesmo nas espiguetas cheias, as lemas e páleas presentes nas sementes do gênero Paspalum podem atrasar ou impedir a sua germinação (PEREZ, 2004).

Com manejo adequado e fertilização, a espécie produz entre 220 a $350 \mathrm{~kg}$ de sementes por hectare que podem ser utilizadas para a propagação da espécie (ALCÂNTARA; BUFARAH, 1988). Cada grama contém em média 600 sementes (BRASIL, 1992).

As sementes apresentam dormência, o que implica em baixo percentual e longo tempo para germinação. A superação natural da dormência ocorre pelo armazenamento das sementes por até três anos (SHERMAN; RISEROS, 1992).

Outros métodos para superação da dormência são estudados para diversas sementes com destaque à escarificação ácida com $\mathrm{H}_{2} \mathrm{SO}_{4}$ (BRASIL, 1992) recomendada para sementes de $P$. notatum e já utilizada com sucesso para sementes de Brachiaria brizantha (MARTINS; SILVA, 2006), Brachiaria plantaginea (SALVADOR et al., 2007), Caesalpinia pyramidalis (ALVES; CARDOSO; BRUNO, 2007), Leucaena leucocephala (TELES et al., 2000), Panicum maximum (USBERTI; MARTINS, 2007) e Stylosanthes scabra (ARAUJO et al., 2002). O tempo de imersão no ácido sulfúrico concentrado com melhores resultados de superação de dormência encontra-se entre 5 e 20 minutos, porém sementes 
de Schizolobium amazonicum apresentaram maior germinação com 60 minutos de escarificação ácida (CRUZ; CARVALHO; QUEIROZ, 2007).

O tratamento com ácido sulfúrico por 15 minutos, apesar de proporcionar redução da dormência, causou deterioração fisiológica latente nas sementes de Brachiaria brizantha cv. Marandu, gerando plântulas anormais (MARTINS; SILVA, 2001).

O nitrato de potássio também é utilizado para superação da dormência de sementes pela ação nos processos oxidativos e respiração celular (ZAIDAN; BARBEDO, 2004). Nas regras para análise de sementes (BRASIL, 1992) há a recomendação para $P$. notatum de umedecer o substrato para germinação com solução de $\mathrm{KNO}_{3}$ a $0,2 \%$ e fornecer luz de 8 a 16 horas para favorecer a germinação. Este tratamento já foi realizado também para outras espécies como a Brachiaria brizantha (MESHEDE et al., 2004).

O objetivo da pesquisa foi verificar o efeito da classificação e da escarificação ácida de cariopses e do tratamento do substrato com nitrato de potássio na germinação das sementes do ecótipo de Paspalum notatum da região de Guarapuava, Paraná.

As inflorescências providas de espiguetas contendo as unidades de dispersão (cariopses) foram colhidas na região de Guarapuava, Paraná. Após degrana manual, a mistura de sementes e material inerte foi submetida à ventilação em soprador de sementes (marca De Leo, $\mathrm{n}^{\circ}$ 059, tipo 01) na abertura três do aparelho quando se identificou a total remoção de material inerte da amostra, descartandose o material soprado. Após esta prelimpeza, as amostras foram submetidas a três tratamentos no soprador de sementes nas regulagens quatro, cinco e seis, o que resultou em três classes de cariopses, a partir deste ponto denominadas de sementes. A massa de mil sementes foi determinada de acordo com as recomendações da Regra para Análise de Sementes (BRASIL, 1992) resultando nas massas de 1,355 g, 2,075 g e 3,138 g para as classes obtidas após ventilação das sementes nas aberturas quatro, cinco e seis do soprador, respectivamente.
As sementes de cada classe receberam escarificação química por imersão em ácido sulfúrico concentrado durante 0 (sem escarificação), 7,5 e 15 minutos. Em seguida as sementes foram lavadas em água corrente, sofreram a assepsia com hipoclorito de sódio a $1 \%$ por três minutos e foram submetidas ao teste de germinação. No teste de germinação estudou-se também o efeito do tratamento com ou sem nitrato de potássio a $0,2 \%$ aplicado diretamente por embebição do papel de germinação até saturação. $\mathrm{O}$ teste de germinação foi desenvolvido no Laboratório de Pesquisa em Produção Vegetal da PUCPR em São José dos Pinhais, Paraná, em germinador modelo Mangersdorf com temperatura de $25{ }^{\circ} \mathrm{C}$ e fotoperíodo natural, utilizando-se o método sobre papel em placas de Petri com três repetições de 50 sementes por tratamento.

A avaliação da germinação foi efetuada aos 7 , 14, 21 e 28 dias após instalação do experimento, considerando-se germinadas as sementes que apresentaram protrusão da raiz primária. As variáveis calculadas foram as seguintes:

- Germinação $(G)$ : calculada pela fórmula $G=$ $(\mathrm{N} / 50) \times 100$, em que: $\mathrm{N}=$ número de sementes germinadas ao final do teste. Unidade: $\%$.

- Índice de velocidade de germinação (IVG): calculado pela fórmula $\mathrm{IVG}=\sum\left(\mathrm{n}_{\mathrm{i}} / \mathrm{t}_{\mathrm{i}}\right)$, em que: $\mathrm{n}_{\mathrm{i}}=$ número de sementes que germinaram no tempo "i"; $\mathrm{t}_{\mathrm{i}}=$ tempo após instalação do teste; $\mathrm{i}=7$ a 28 dias. Unidade: adimensional.

- Tempo médio de germinação (TMG): calculado pela fórmula $\mathrm{TMG}=\left(\sum \mathrm{n}_{\mathrm{i}} \mathrm{t}_{\mathrm{i}}\right) / \sum \mathrm{n}_{\mathrm{i}}$, onde: $\mathrm{n}_{\mathrm{i}}=$ número de sementes germinadas por dia; $t_{i}=$ tempo de incubação; i= 7 a 28 dias. Unidade: dias.

O delineamento experimental adotado foi o completamente casualizado em arranjo fatorial $3 \times 3 \times 2$ : três classes de sementes (obtidas após tratamento em soprador de sementes nas aberturas 4, 5 e 6), três tempos de escarificação ácida $(0,7,5$ e 15 minutos) e duas concentrações de $\mathrm{KNO}_{3}$ no teste de germinação $(0$ e $0,2 \%)$ resultando em 18 tratamentos com três repetições de 50 sementes. 
As médias dos tratamentos e suas interações com diferenças significativas pelo teste $\mathrm{F}$ na análise de variância foram submetidas ao teste Tukey ao nível de significância de 5\%. Os dados foram transformados para análise em $\log (\mathrm{x}+10)$. Realizou-se também a análise de correlação ente as variáveis estudadas.

Houve efeito significativo da interação entre os fatores classificação de cariopses e escarificação ácida na superação da dormência e germinação de sementes de $P$. notatum, mas o tratamento com nitrato de potássio não interferiu significativamente nos resultados encontrados (prob. $>\mathrm{F}_{\text {nitrato }}=0,635$ para germinação, prob. $>\mathrm{F}_{\text {nitrato }}=0,522$ para IVG e prob. $>\mathrm{F}_{\text {nitrato }}=0,071$ para TMG). Portanto, os dados apresentados nas tabelas referem-se às médias dos valores observados para sementes tratadas com $0 \mathrm{e}$ $0,2 \%$ de $\mathrm{KNO}_{3}$. As sementes classificadas na classe quatro e não escarificadas não germinaram durante os 28 dias de observação, enquanto as sementes classificadas em soprador regulado na abertura seis, que permite maior velocidade da corrente de ar, e 15 minutos de imersão no $\mathrm{H}_{2} \mathrm{SO}_{4}$ atingiram germinação média de 12,2\% (Tabela 1). Não houve presença de plântulas anormais, o que caracterizaria a deterioração fisiológica latente, já verificada para sementes escarificadas de Brachiaria brizantha cv. Marandu (MARTINS; SILVA, 2001).

Tabela 1. Germinação, índice de velocidade de germinação (IVG) e tempo médio de germinação (TMG) de sementes de um ecótipo de Paspalum notatum da região de Guarapuava, Paraná, após classificação em soprador de sementes e escarificação ácida das cariopses.

\begin{tabular}{|c|c|c|c|c|c|c|}
\hline \multirow{2}{*}{$\begin{array}{l}\text { Classes de } \\
\text { cariopses }\end{array}$} & \multicolumn{6}{|c|}{ Tempo de escarificação com $\mathrm{H}_{2} \mathrm{SO}_{4}(\mathrm{~min})$} \\
\hline & \multicolumn{2}{|c|}{$\mathbf{0}$} & \multicolumn{2}{|c|}{$\mathbf{7 , 5}$} & \multicolumn{2}{|c|}{15} \\
\hline & \multicolumn{6}{|c|}{ Germinação (\%) } \\
\hline 4 & 0,0 & $\mathrm{Ab}^{*}$ & 0,7 & $\mathrm{Ab}$ & 0,7 & $\mathrm{Ac}$ \\
\hline 5 & 2,2 & A a & 2,2 & $\mathrm{Ab}$ & 3,0 & $\mathrm{Ab}$ \\
\hline 6 & 1,3 & $\mathrm{Cab}$ & 6,3 & $\mathrm{~B} \mathrm{a}$ & 12,2 & $\mathrm{~A} \mathrm{a}$ \\
\hline \multicolumn{7}{|c|}{$\mathrm{CV}_{\text {germinac̃̃o }}=7,18 \%$} \\
\hline & \multicolumn{6}{|c|}{ IVG } \\
\hline 4 & 0,00 & $\mathrm{~A} \mathrm{a}$ & 0,06 & $\mathrm{Ab}$ & 0,08 & $\mathrm{Ab}$ \\
\hline 5 & 0,18 & A a & 0,28 & $\mathrm{Ab}$ & 0,35 & $\mathrm{Ab}$ \\
\hline 6 & 0,10 & $\mathrm{Ca}$ & 0,73 & $\mathrm{~B}$ a & 1,41 & A a \\
\hline \multicolumn{7}{|c|}{$\mathrm{CV}_{\mathrm{IVG}}=1,10 \%$} \\
\hline & \multicolumn{6}{|c|}{ TMG (dias) } \\
\hline $4 * * *$ & $-* *$ & \multirow{3}{*}{ ns } & 14,0 & & 14,0 & \\
\hline 5 & 14,2 & & 10,7 & ns & 10,9 & ns \\
\hline 6 & 15,8 & & 11,8 & & 10,9 & \\
\hline
\end{tabular}

ns Diferenças não significativas entre os tratamentos.

* Médias seguidas por letras distintas, maiúsculas nas linhas e minúsculas nas colunas, diferem entre si pelo teste Tukey ao nível de significância de 5\%. Dados mostrados são originais, mas foram transformados para análise em $\log (\mathrm{x}+10)$.

** Nenhuma semente germinou após 28 dias de avaliação.

*** Tratamento não considerado na análise estatística em função do elevado número de parcelas que não apresentaram germinação de sementes durante os 28 dias do teste. 
Verificou-se que nas amostras de sementes com menor pressão de classificação (classe quatro) a escarificação ácida não trouxe benefício, proporcionando germinação de apenas $0,7 \%$, semelhante estatisticamente às sementes não escarificadas. Neste casos, o rompimento das barreiras à embebição ocorreu, mas as espiguetas estavam vazias. Já nas sementes com maior pressão de classificação (classe seis) a escarificação proporcionou aumento significativo na germinação em função da maior freqüência de espiguetas cheias. Assim, o tratamento com o soprador de sementes foi eficiente por retirar da massa de sementes parte daquelas vazias.

A ausência de germinação das sementes não tratadas verificadas neste estudo está de acordo com os resultados de Maeda, Pereira e Medina (1997) que não obtiveram germinação de sementes recém colhidas de $P$. notatum. Para Alcântara e Bufarah (1988) a germinação inicial de sementes de $P$. notatum é baixa, mas se eleva com o armazenamento podendo atingir até 50\%. Maeda, Pereira e Medina (1997) encontraram germinação máxima de 6,5\% após 210 dias de tratamento com calor a $40^{\circ} \mathrm{C}$ em condições herméticas e até $57 \%$ de germinação após 20 meses de armazenamento em condições não controladas. Sementes submetidas a temperaturas de $60^{\circ} \mathrm{C}$ por até 24 dias apresentaram germinação máxima de $2 \%$ sem apresentar deterioração. $\mathrm{O}$ baixo percentual de espiguetas férteis (5 a 24\%) encontrado em plantas do gênero Paspalum (CARMONA; MARTINS; FÁVERO, 1999) aliado à presença de lemas e páleas nas sementes que atrasam a germinação (PEREZ, 2004) são fatores decisivos para determinação de baixos percentuais de germinação de sementes sem tratamentos prégerminativos.

Embora a produção de sementes por hectare de $P$. notatum e o número de sementes por grama sejam elevados (ALCÂNTARA; BUFARAH, 1988; BRASIL, 1992), o baixo percentual de germinação das sementes não classificadas $(0,5 \%)$ ou não escarificadas $(1,2 \%)$ diminuem o valor cultural do lote de sementes e dificultam a implantação da cultura. O aumento do poder germinativo para $12,2 \%$ pode contribuir significativamente para a eficiência dos processos de implantação da pastagem

O tratamento com nitrato de potássio a $0,2 \%$ não interferiu na superação da dormência e germinação das sementes estudadas. Embora o uso do $\mathrm{KNO}_{3}$ seja recomendado para a análise de sementes de P. notatum (BRASIL, 1992) por sua ação nos processos oxidativos e na respiração celular da semente (ZAIDAN; BARBEDO, 2004), as sementes do ecótipo estudado não responderam ao estímulo oferecido.

De forma semelhante à germinação, o índice de velocidade de germinação (IVG) foi significativamente afetado pela interação entre os tratamentos classificação e escarificação ácida. O máximo IVG $(1,41)$ foi obtido nas sementes com maior pressão de classificação (classe seis) e escarificadas por 15 minutos no ácido sulfúrico (Tabela 1). Esta combinação de tratamentos resultou em germinação mais elevada e mais rápida, implicando em uma correlação positiva elevada $(r=$ $0,99)$ entre as variáveis germinação e IVG.

Embora não tenha sido possível a comparação estatística dos valores de tempo médio de germinação (TMG) para as sementes da classe quatro em função do elevado número de parcelas com ausência de germinação, observou-se o TMG de 14 dias nestas parcelas. Não houve efeito significativo da classificação das cariopses nas classes cinco e seis e dos tratamentos com $\mathrm{H}_{2} \mathrm{SO}_{4}$ e $\mathrm{KNO}_{3}$ no TMG, que ficou entre 11,9 e 12,8 dias (Tabela 1).

As correlações entre o TMG e as variáveis germinação e IVG para as sementes tratadas com ácido por 15 minutos foram semelhantes, porém não muito elevadas ( $\mathrm{r}=-0,65 \mathrm{e}-0,66$, respectivamente). As correlações entre o TMG e a germinação e o IVG para as sementes tratadas por 7,5 minutos foram baixas $(-0,37$ e $-0,50$, respectivamente) implicando que este tempo de tratamento não apresentou efeito homogêneo na superação da dormência e germinação das sementes de P. notatum. . 
Concluiu-se que a classificação em soprador de sementes na abertura seis e a escarificação em ácido sulfúrico durante 15 minutos das cariopses favorecem a germinação das sementes de $P$. notatum do ecótipo de Guarapuava, e não houve interferência do uso do nitrato de potássio.

\section{Referências}

ALCÂNTARA,P.B.;BUFARAH, G. Plantasforrageiras: gramíneas e leguminosas. São Paulo: Nobel, 1988.

ALVES, E. U.; CARDOSO, E. A.; BRUNO, R. L. A. Superação da dormência em sementes de Caesalpinia pyramidalis Tul. Revista Árvore, Viçosa, v. 31, n. 3, p. 405-415, 2007.

ANDRADE, C. M. S.; VALENTIM, J. F.; CARNEIRO, J. C.; VAZ, F. A. Crescimento de gramíneas e leguminosas forrageiras tropicais sob sombreamento. Pesquisa Agropecuária Brasileira, Brasília, v. 39, n. 3, p. 263-270, 2004.

ARAUJO, E. F.; ARAUJO, R. F.; SILVA, R. F.; GALVÃO, J. C. C. Superação da dureza de sementes e frutos de Stylosanthes scabra J. Vogel e seu efeito na germinação. Revista Brasileira de Sementes, Brasília, v. 24, n. 2, p. 77-81, 2002.

BOGGIANO, P.; MARASCHIN, G.; NABINGER, C.; RIBOLDI, J.; CADENAZZI, M.; ROSA, L. M. Effect of the herbage allowance and nitrogen fertilization on tiller density and weight of Paspalum notatum Flügge in a natural pasture in Rio Grande do Sul. In: SIMPÓSIO INTERNACIONAL "GRASSLAND ECOPHYSIOLOGY AND GRAZING ECOLOGY", 1999, Curitiba. Anais... Curitiba: UFPR, 1999. p. 391394.

BRASIL. Ministério da Agricultura e da Reforma Agrária. Regras para análise de sementes. Brasília: Secretaria Nacional de Defesa Agropecuária, 1992. 365p.

CARMONA, R.; MARTINS, C. R.; FÁVERO, A. P. Características de sementes de gramíneas nativas do cerrado. Pesquisa Agropecuária Brasileira, Brasília, v. 34, n. 6, p. 1067-1074, 1999.

CRUZ, E. D.; CARVALHO, J. E. U.; QUEIROZ, R. J. B. Escarificação com ácido sulfúrico de sementes de Schizolobium amazonicum Huber ex Ducke - Fabaceae. Scientia Agricola, Piracicaba, v. 64, n. 3, p. 308-313, 2007.

FIDALSKI, J.; MARUR, C. J.; AULER, P. A. M.; TORMENA, C. A. Produção de laranja com plantas de cobertura permanente na entrelinha. Pesquisa Agropecuária Brasileira, Brasília, v. 41, n. 6, p. 927-935, 2006.

FONSECA, E. L.; ROSA, L. M. G.; FONTANA, D. C. Caracterização espectral de Paspalum notatum em diferentes níveis de adubação nitrogenada. Pesquisa Agropecuária Brasileira, Brasília, v. 37, n. 3, p. 365-371, 2002.

HADDAD, C. M.; DOMINGUES, J. L.; CASTRO, F. G. F.; TAMASSIA, L. F. M. Características de produção e valor nutritivo do capim pensacola (Paspalum notatum Fluegge var. Saurae Parodi) em função da idade de corte. Scientia Agricola, Piracicaba, v. 56, n. 3, p. 753-761, 1999.

HERINGER, I.; JACQUES, A. V. A. Composição florística de uma pastagem natural submetida a queima e manejos alternativos. Ciência Rural, Santa Maria, v. 32, n. 2, p. 315-321, 2002.

LORENZI, H.; SOUZA, H. M. Plantas ornamentais no Brasil: arbustivas, herbáceas e trepadeiras. Nova Odessa: Instituto Plantarum, 1999.

MAEDA, J. A.; PEREIRA, M. F. D. A.; MEDINA, P. F. Conservação e superação da dormência de sementes de Paspalum notatum Flügge. Revista Brasileira de Sementes, Brasília, v. 19, n. 2, p. 165-171, 1997.

MARÇALlO, F. A.; PELISSARI, A.; MORAES, A. Aplicação de Glifosato em campo naturalizado de pensacola, para estabelecimento de forrageiras hibernais em sobre-semeadura. Scientia Agraria, Curitiba, v. 7, n. 1/2, p. 55-59, 2006.

MARTINS, L.; SILVA, W. R. Comportamento da dormência em sementes de braquiária submetidas a tratamentos térmicos e químicos. Pesquisa Agropecuária Brasileira, Brasília, v. 36, n. 7, p. 997-1003, 2001.

. Ações fisiológicas do calor e do ácido sulfúrico em sementes de Brachiaria brizantha cultivar Marandu. Bragantia, Campinas, v. 65, n. 3, p. 495-500, 2006.

MENEZES, L. F. T.; ARAUJO, D. S. D. Regeneração e riqueza da formação arbustiva de Palmae em uma cronoseqüência pós-fogo na restinga da Marambaia, Rio de Janeiro, RJ, Brasil. Acta Botanica Brasilica, Porto Alegre, v. 18, n. 4, p. 771-780, 2004.

MESHEDE, D. K.; SALES, J. G. C.; BRACCINI, A. L.; SCAPIM, C. A.; SCHUAB, S. R. Tratamentos para superação da dormência das sementes de capimbraquiária cultivar Marandu. Revista Brasileira de Sementes, Brasília, v. 26, n. 2, p. 76-81, 2004.

NABINGER, C.; VIEIRO, J. M.; COSTA, J. A. A. Validation of predictive models of aerial dry matter 
accumulation for Paspalum notatum Flügge ecotypes. In: SIMPÓSIO INTERNACIONAL "GRASSLAND ECOPHYSIOLOGY AND GRAZING ECOLOGY", 1999, Curitiba. Anais... Curitiba:UFPR, 1999. p. 399402.

OLIVA, M. A.; FIGUEIREDO, J. G. Gramíneas bioindicadoras da presença de flúor em regiões tropicais. Revista Brasileira de Botânica, v. 28, n. 2, p. 389-397, 2005.

PEREZ, S. C. J. G. A. Envoltórios. In: FERREIRA, A. G.; BORGHETTI, F. Germinação: do básico ao aplicado. Porto Alegre: Artmed, 2004. p. 125-134.

QUADROS, F. L. F.; BICA, G. S.; DAMÉ, P. R. V.; DOROW, R.; KERSTING, C.; PÖTTER, L. Levantamento das pastagens naturais da região de Santa Maria-RS, Brasil. Ciência Rural, Santa Maria, v. 33, n. 5, p. 921-927, 2003.

SALVADOR, F. L.; VICTORIA FILHO, R.; ALVES, A. S. R.; SIMONI, F.; SAN MARTIN, H. A. M. Efeito da luz e da quebra de dormência na germinação de sementes de espécies de plantas daninhas. Planta Daninha, Rio de Janeiro, v. 25, n. 2, p. 303-308, 2007.

SCHEFFER-BASSO, S. M.; TRENTINI, V.; BARÉA, K. Manejo de Paspalum dilatatum poir. Biótipo virasoro. 2. Produção de sementes. Revista Brasileira de Zootecnia, Viçosa, v. 36, n. 4, p. 1022-1028, 2007.
SHERMAN, P. J.; RISEROS, F. Gramineas tropicales. Roma: FAO, 1992. 849 p. (Colleción FAO: Producción y Protección Vegetal, n. 23).

SOARES FILHO, C. V.; RODRIGUES, L. R. A. Avaliação agronômica do Paspalum notatum cv Tifton-9 sob pastejo. In: SIMPÓSIO INTERNACIONAL "GRASSLAND ECOPHYSIOLOGY AND GRAZING ECOLOGY", 1999, Curitiba. Anais... Curitiba: UFPR, 1999. p. 244-248.

SOUZA FILHO, A. P. S. Interferência potencialmente alelopática do capim-gengibre (Paspalum maritimum) em áreas de pastagens cultivadas. Planta Daninha, Rio de Janeiro, v. 24, n. 3, p. 451-456, 2006.

TELES, M. M.; ALVES, A. A.; OLIVEIRA, J. C. G.; BEZERRA, A. M. E. Métodos para quebra de dormência em sementes de Leucena [Leucaena leucocephala (Lam.) de Wit]. Revista Brasileira de Zootecnia, Viçosa, v. 29, n. 2, p. 387-391, 2000.

USBERTI, R.; MARTINS, L. Efeitos da escarificação com ácido sulfúrico na liberação da dormência de sementes de Brachiaria brizantha, B. humidicola e Panicum maximum. Revista Brasileira de Sementes, Brasília, v. 29, n. 2, p. 143-147, 2007.

ZAIDAN, L. B. P.; BARBEDO, C. J. Quebra de dormência em sementes. In: FERREIRA, A. G.; BORGHETTI, F. Germinação: do básico ao aplicado. Porto Alegre: Artmed, 2004. p. 135-146. 
